Stahl, T., Rütten, A., Nutbeam, D., Bauman, A., Kannas, L., Abel, T., Lüschen, G., Rodríguez Diaz, J.A., Vinck, J., Zee, J. van der

The importance of the social environment for physically active lifestyle: results from an international study.

Social Science \& Medicine: 52, 2001, nr. 1, p. 1-10

\begin{tabular}{l|l} 
Postprint Version & 1.0 \\
Journal website & $\underline{\text { http://dx.doi.org }}$ \\
\hline Pubmed link & $\begin{array}{l}\text { http://www.ncbi.nlm.nih.gov/entrez/query.fcgi?db=pubmed\&cmd=Retrieve\&dop } \\
\text { t=Abstract\&list uids=11144909\&query hl=10\&itool=pubmed docsum }\end{array}$ \\
\hline DOI & $\underline{10.1016 / \text { S0277-9536(00)00116-7 }}$
\end{tabular}

\title{
The importance of the social environment for physically active lifestyle - results from an international study
}

\author{
T. STÅHL ${ }^{A, *}$, A. RÜTTEN ${ }^{\mathrm{B}}$, D. NUTBEAM ${ }^{\mathrm{C}}$, A. BAUMAN ${ }^{\mathrm{D}}$, L. KANNAS ${ }^{\mathrm{A}}$, T. ABEL ${ }^{\mathrm{E}}$, G. LÜSCHEN ${ }^{\mathrm{F}}$, DiAZ
} J.A. RODRIQUEZ ${ }^{\mathrm{G}}$, J. VINCK ${ }^{\mathrm{H}}$, J. VAN DER ZEE ${ }^{\mathrm{I}}$

${ }^{a}$ University of Jyväskylä, Department of Health Sciences, P.O. Box 35, 40351 Jyväskylä, Finland

${ }^{\mathrm{b}}$ Technical University of Chemnitz, Faculty of Philosophy, Sport Science III, D-09107 Chemnitz, Germany

${ }^{c}$ University of Sydney, Department of Public Health \& Community Medicine, Sydney NSW 2006, Australia

d University of New South Wales, Epidemiology Unit, Liverpool BC 1871, Sydney NSW 2006, Australia

${ }^{\mathrm{e}}$ University of Bern, Department of Health Research, ISPM, Niesenweg 6, CH-3012 Bern, Switzerland

' University of Alabama at Birmingham, Department of Sociology, 1212 University Blvd., Birmingham, AL 35294-3350, USA

${ }^{9}$ University of Barcelona, Department of Sociology, Avenida Diagonal 690, ESP-08034 Barcelona, Spain

hLimburg University Centre, Department of Human \& Social Sciences, B-3590 Diepenbeck, Belgium

'Netherlands Institute of Primary Health Care, P.O. Box 1568, NL-3500 BN Utrecht, The Netherlands

*Corresponding author. Tel.: +358-14-2602168; fax: +358-14-2602189. E-mail address:

stahl@pallo.jyu.fi (T. Ståhl).

\begin{abstract}
Physically active lifestyles are regularly associated with improved health and quality of life. Differences in lifestyles in society can partly be understood through the differences in the social and physical environment. This study examines the relationships between reported physical activity, and the extent of perceived support for physical activity in the physical and policy environment (e.g. facilities, programmes and other opportunities), and in the social environment.

The data for the study come from a cross-cultural health policy study called MAREPS. In total, 3342 adults, 18 years or older, from six countries (Belgium, Finland, Germany, The Netherlands, Spain, Switzerland) were interviewed via telephone. Respondents were categorised as active or inactive according to self-reported physical activity. Social environmental factors and physical and policy environmental factors were also assessed. The analysis of the data was informed by social cognitive theory, although the study was not originally designed for this purpose.

Sixty-eight percent of females and $70 \%$ of males were active. The proportions of active and inactive varied by countries to a great extent. The strongest independent predictor of being physically active was social environment. Those who perceived low social support from their personal environment (i.e. family, friends, school and workplace) were more than twice as likely to be sedentary compared to those who reported high social support from their personal environment. Specific knowledge of the programmes and actions for physical activity and sport was also a strong predictor of being active. A supportive
\end{abstract}


Stahl, T., Rütten, A., Nutbeam, D., Bauman, A., Kannas, L., Abel, T., Lüschen, G.,

Rodríguez Diaz, J.A., Vinck, J., Zee, J. van der

The importance of the social environment for physically active lifestyle: results from

an international study.

Social Science \& Medicine: 52, 2001, nr. 1, p. 1-10

physical and policy environment was not associated with participation in physical activity as strongly as had been anticipated. The variation between countries was stronger predictor of being active than the physical and policy environment variables.

This study generates the hypotheses and raises the questions that in a preliminary way, there appears to be some relationships between aspects of physical and social environment and physical activity participation. However, future research is needed to refine and clarify this.

\section{INTRODUCTION}

There is increasing recognition that physically active lifestyles are important for population health. Increased efforts are needed to understand the factors associated with being active in society. Several health education and health promotion interventions to promote physical activity have been designed according to social cognitive theory. Social cognitive theory is commonly used to examine and explain relationships between the physical environment, individual behaviours and perceptions of the social environment. Most of these intervention studies have examined the role of the social environment (social support from family and friends) role in health behaviour change, but other environmental factors are rarely considered in the interventions. Most of the cross- sectional and prospective studies have included social environmental factors in the analysis but not other environmental factors (Baranowski, Anderson \& Carmack, 1998).

This paper provides a review of relevant literature, and describes results from a cross-cultural health policy study called MAREPS (A Methodology for the Analysis of Rationality and Effectiveness of Prevention and Health Promotion Strategies). These data are used to examine relationships (existence, strength, consistency) between reported physical activity, and the extent of perceived support for physical activity in the physical (and related policy) environment, and in the social environment corresponding broadly to the key elements of social cognitive theory. Although the MAREPS survey was not originally designed according to the social cognitive theory it contains questions which address these core components (Rütten et al., 2000).

\section{THE SOCIAL ENVIRONMENT, SOCIAL SUPPORT AND PHYSICAL ACTIVITY}

Social relationships and social support are one of the key elements of the social environment that influence health behaviours and health status. Several reviews have addressed the positive influence of social relation- ships on health (Antonucci, 1990; House, Umberson \& Landis, 1988a; Turner \& Marino, 1994; Quick, Nelson, Matuszek, Whittington \& Quick, 1996). Although there are some inconsistencies in the findings and conclusions of the reviews, Heaney and Israel (1996) conclude that social support together with social networks have an important causal effect on health, exposure to stress and the relationship between stress and health. The reviews conducted also provide consistent evidence that social relationships influence health behaviour choices (Heaney \& Israel, 1996).

Although the evidence concerning the positive effects of social support on health is convincing, the mechanisms responsible for this effect are still not clear (House, Landis \& Umberson, 1988b; Quick et al., 1996).

The influence of social support on health behaviour may be positive or negative (Antonucci, Akiyama \& Lansford, 1998; House et al., 1988a; Quick et al., 1996; Baranowski, Perry \& Parcel, 1996). For example an adolescent may learn from others by observing (vicarious learning) that smoking is fun, offers an adult appearance and is generally desirable according to peers (perceived social norm). Alternatively people may observe their peers quitting smoking, and receive consistent negative feedback about the social accept- ability of smoking.

Almost every study that has examined the relationship between physical activity and social support has found a strong positive association. This relationship has been studied in both cross-sectional and prospective studies (Sallis \& Owen, 1998; DiLorenzo, Stucky-Ropp, Vander Wal \& Gothman, 1998; Sallis, Hovell \& Hofstetter, 1992). Friend and family support have been consistently found to influence participation in physical activity across wide range of population groups (Sallis \& Owen, 
Stahl, T., Rütten, A., Nutbeam, D., Bauman, A., Kannas, L., Abel, T., Lüschen, G., Rodríguez Diaz, J.A., Vinck, J., Zee, J. van der

The importance of the social environment for physically active lifestyle: results from an international study.

Social Science \& Medicine: 52, 2001, nr. 1, p. 1-10

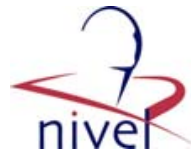

1998; Sternfeld, Ainsworth \& Quesenberry, 1999; Steptoe et al., 1997). By contrast, lack of social support from family and friends is associated with lower levels of physical activity. There is also evidence that social support may be more influential for women, especially support from the family (Leslie, Owen, Salmon, Bauman, Sallis \& Sing Kai Lo, 1999; Sallis et al., 1992; Steptoe et al., 1997). Apart from family and peers, there are some findings of physician's positive influence on activity (Frankish, Milligan \& Reid, 1998; Sallis \& Owen 1998).

Most published studies have examined relationships between vigorous physical activity and social support (Sallis \& Owen, 1998). In the past decade, recommendations concerning regular physical activity have changed to advocate less vigorous more moderate physical activity. It is not yet clear whether previous findings on the determinants of vigorous physical activity would be directly transferable to moderate physical activity (Laitakari, Vuori \& Oja, 1996; Coureya \& McAuley, 1994).

\section{THE PHYSICAL AND POLICY ENVIRONMENT AND PHYSICAL ACTIVITY}

Environmental interventions are often referred to as "passive" interventions since they are not developed in a way that requires people to take any action on an individual basis or to make active behavioural changes (e.g. safe pedestrian and bike paths, and injury resistant design). Actions that lead to changes in the environment are generally taken at a societal level to reduce exposure to health risks, or to promote healthy behaviour. In general, environmental interventions have a greater chance of having equal effect on all people regardless of gender, income group or other socio-economic status. Hence, environmental interventions are considered to be an important form of public health action, complementary to more individual forms of intervention such as health education (Holman, 1997; Schmid, Pratt \& Howze, 1995).

Interventions that have used both educational and environmental measures have been more successful in achieving changes in health behaviour than single element interventions. Examples can be found in the areas of diet, smoking and physical activity (Brownson et al., 1995, 1998; Leupker et al., 1996; Edmundson, 1996; Vartiainen, Puska, Jousilahti, Korhonen, Tuomilehto \& Nissinen, 1994; Simons-Morton et al., 1991; Biener, Abrams, Follick \& Dean, 1989).

The impact of the environment on participation in physical activity has been relatively poorly examined. Following Sallis, Bauman and Pratt (1998) definition, environment can be seen as the extent to which there are incentives or restrictions that make health behaviour easier or less easy. Incentive environments are those which provide best access to facilities for physical activity such as sport fields, bicycle paths and swimming pools. Restricting environments are those which con- strain access, or provide attractive sedentary environments, for example busy highway systems, sedentary games rooms and many office-based workplaces. Strongly related to these environments are the regulations and policies that create opportunities or restrictions for physically active behaviour (Sallis et al., 1998). We have used in this study "a supportive physical and policy environment" to reflect both the physical/ organisational environment and the policies which shape this environment.

Evidence of the role of this physical and policy environment in physical activity is still quite limited. The strongest evidence comes from observational studies of pre-school children. These show positive correlates between being outdoors and physical activity. Children's activity levels were also associated with the number of play spaces and the amount of time children used those play spaces (Sallis et al., 1998) Studies from adult populations have also found associations between environmental variables and physical activity, although these associations have not been very strong or consistent (Sallis et al., 1989, 1990, 1992; King et al., 1995). Intervention studies conducted in schools, restricted communities (e.g. military bases) and communities have succeeded in increasing the physical activity of the intervention groups to some extent (Linenger, Chesson \& Nice, 1991; Stone, McKenzie, Welk \& Booth, 1998; Sallis et al., 1998). Interventions conducted at worksites and directed only to physical environment (building fitness facilities) have not consistently demonstrated increased physical activity of employees (Shephard, 1996; Dishman, Oldenburg, O'Neal \& Shephard, 1998).

A study that examined predictors of adoption of vigorous physical activity (Sallis et al., 1992) found that environmental variables (self-reported) were significant predictors of adoption for sedentary men, but not for women for whom social variables were much stronger predictors of adoption. In a recent study (Sallis, Johnson, Calfas, Caparosa \& Nichols, 1997) none of the measured environmental 
Stahl, T., Rütten, A., Nutbeam, D., Bauman, A., Kannas, L., Abel, T., Lüschen, G., Rodríguez Diaz, J.A., Vinck, J., Zee, J. van der

The importance of the social environment for physically active lifestyle: results from an international study.

Social Science \& Medicine: 52, 2001, nr. 1, p. 1-10

variables (self-reported) explained large amounts of variance in physical activity, either in correlational or regression analysis. Results from qualitative studies in Australia suggest that proximity and accessibility of facilities are important factors for the use of the facility and subsequent physical activity. Personal preferences also play an important role, e.g. attributes of the facility (the cost, its appearance, amenities and perception about its other users and staff) and previous experience (Corti, Donovan \& Holman, 1996; Corti, Donovan, Castine, Holman \& Shilton, 1995).

\section{METHODS}

\section{Procedure and sample}

This research was conducted using data from the international MAREPS project. The MAREPS project was established to examine different elements of health policy related to health promotion, and analyses development, implementation, impact and evaluation of policies. The fieldwork and analysis were funded by the European Union (Biomed2 programme) and participating countries. The project includes policymaker and public surveys conducted in Belgium, Finland, Ger- many, The Netherlands, Spain and Switzerland. Four policies were selected for examination, namely, the creation of healthy living and working conditions, early detection of breast cancer, prevention of smoking and promotion of sports and physical activity (Rütten et al., 2000). This study reports results from data on the issue of sports and physical activity only.

Data for this comes from a public survey that was conducted via a telephone-administered semistandardised interview schedule in the autumn 1997 and spring 1998. Random sampling was employed in every region of the country selected, and resulted in the sample sizes shown in Table 1. For practical and financial reasons one region or administrative entity, was selected to represent the entire nation of the country, with the exception of the Netherlands where the sample was drawn to represent the whole population. In Finland and Spain the sample was drawn from official registers, other countries used telephone CD-ROMs. The last-birthday method was used for in-household selection (for more information see Rütten et al., 2000).

\section{[ TABLE 1 ]}

The overall response rate, 53.5\%, is relatively low (Babbie, 1990; Fowler, 1984). However, it is worth mentioning that not all that could not be interviewed were refusals; there were prolonged absences due to travel or for work reasons. Also those who did not speak the survey language are included in the selected sample denominator.

Among the realised sample, there is modest over-represention of women in Germany, The Netherlands and Switzerland. The Spanish respondents are relatively young, while the Finnish sample was relatively old. There were not notable variations in educational status across nations.

This paper presents the overall findings from the study and the samples of the countries are considered as one population. Differences between countries are recognised where these emerge as important in understanding the findings. More detailed analyses of country differences are to be reported separately.

\section{Measures}

The original study was not designed to assess the components of social cognitive theory. However, it uses similar measures to those used in studies that are more overtly designed according to social cognitive theory, or with other health education or health promotion models/theories (see e.g. Sallis et al., 1989, 1992; Luepker et al., 1996; Leslie et al., 1999). The social support measures are similar to those widely used in other studies, with the exception that other studies have not usually included other measures beyond family and friends. Environmental measures are often related to perceived access to facilities in the local environment (which is also one of our measures). In addition, this study included measures related to policies, and possibilities/restrictions for physical activity, which are not used in other studies (Sallis \& Owen, 1998; Leslie et al., 1999; Sallis et al., 1992; Sallis, Grossman, Pinski, Patterson \& Nader, 1987). 
Stahl, T., Rütten, A., Nutbeam, D., Bauman, A., Kannas, L., Abel, T., Lüschen, G., Rodríguez Diaz, J.A., Vinck, J., Zee, J. van der

The importance of the social environment for physically active lifestyle: results from

an international study.

Social Science \& Medicine: 52, 2001, nr. 1, p. 1-10

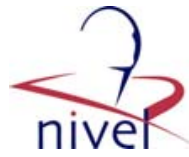

\section{Social environment}

The social environment items were developed to reflect perceived social support for participation in physical activity. In total, ten items measured perceived motivation to participate in sports and physical activity from family and friends, as well as less direct social influences such as newspapers, TV, workplace, school, community, politicians, doctor and health insurance. Items were presented on a five-point Likert scale ( $5=$ very much, $1=$ not at all). In order to discover patterns among the variations in values of the items and for the purpose of further analysis, the items were factor analysed and scales were constructed. (Table 2) The intercorrelations of the factors varied from $r=|0.32|$ to $\mathrm{r}=$ $|0.38|$ and the Cronbach $\alpha$ reliability coefficients for the subscales ranged from 0.568 to 0.810 . Social support was categorised as low or high using the median as a cutoff point.

\section{[ TABLE 2 ]}

\section{Supportive physical and policy environment}

Items measuring perceived opportunities to be physically active from the physical and policy environment were developed to examine both the local level and more general level (Table 2). Residential area and community measures represent more concrete features of environment, i.e. the facilities for physical activity (e.g. parks, cycling paths, exercise programmes etc.) while general/ government measures represent more abstract features of environment, i.e. regulations/incentives, policies and possibilities for physical activity.

General awareness of the opportunities for physical activity and sport, and of the contribution of health policy to promote physical activity and sport were both measured by one item (Table 2). These items were presented on a five-point Likert scale (5=definitely true, $1=$ not true at all) and perceived support was categorised as high or low using median as a cutoff point. Three local opportunity items were summed to yield a measure of local opportunities to be physically active. Cronbach $\alpha$ reliability coefficients of the scale was 0.74 . The local opportunity items were presented on a five- point Likert scale ( $5=$ definitely true, $1=$ not true at all). Local opportunities were categorised as low or high using median as a cutoff point.

\section{Physical activity}

Respondents' physical activity was assessed by one very general question: “'Do you do any gymnastics, physical activity or sports?" The measure distinguished active people from inactive, since the respondents answered either yes (1) or no (0). Interviewers were advised to explain that physical activity is defined in a very broad sense including, e.g. physically active commuting to work, gardening, competitive sport etc.

Because, there are no validated international measures of physical activity at present and cross cultural validation studies have not yet been done, a very broad question was selected. This simple, single item measure is a somewhat crude measure but because the purpose of this study was to look at factors associated with physical activity not to measure physical activity precisely, the measure was found to be acceptable, if somewhat limited. Because this paper is not reporting prevalence data, the effect of measurement error is likely to be non- differential.

\section{Scale constructions}

Table 2 shows the subscales constructed from these data. The factor loadings are derived from oblique rotation factor analyses. A three factor model was chosen as three factors were extracted with eigenvalues greater than one, and were retained as the factors for use in scale development. Derived factors were orthogonal to each other. The factors explained $54 \%$ of the variance in all the items. The internal consistency of each scale ranged from modest to excellent Cronbach's $\alpha$ values. 
Stahl, T., Rütten, A., Nutbeam, D., Bauman, A., Kannas, L., Abel, T., Lüschen, G., Rodríguez Diaz, J.A., Vinck, J., Zee, J. van der

The importance of the social environment for physically active lifestyle: results from

an international study.

Social Science \& Medicine: 52, 2001, nr. 1, p. 1-10

\section{RESULTS}

\section{Characteristics of respondents}

The final sample size was 3343 adults, 18 years or older (56.9\% female, $43.1 \%$ male), reflecting overall response rate $53.5 \%$. The median age of the respondents was 45 years (range 18-96 years). Eighteen percent of the respondents were aged $18-29$ years; $31 \%$ were aged $30-44$ years, $26 \%$ were aged $45-59$ years, and $25 \%$ were aged 60 or over. The median time of education was 12 years ranging from 0 to 20 years. Thirty-seven percent of the respondents had only basic school education (9 years or less); $27 \%$ had studied $10-14$ years, and $36 \%$ for more than 15 years. The majority of the respondents (68.7\%) were classified as physically active, although there were large differences between countries; highest percentage were seen in Finland (88\%) and the lowest in Spain, with only $37.4 \%$ of active people (Table 3 ).

\section{[ TABLE 3 ]}

\section{Bivariate analysis}

There were statistically significant differences on the independent variables between active and inactive people (Table 3). Those who had high perception of local opportunities, were well informed about pro- grammes and actions, perceived high support from health policy for physical activity and sports, and had high social support from personal environment were more likely to be active. Those who perceived high social support from media were more likely to be sedentary. The better educated a person was the more likely he/she was active. Gender and age were not associated significantly with sedentary behaviour.

\section{Multivariate analysis}

Characteristics of inactive people compared to active people were examined using a logistic regression model. The external social environment-scale was not included in the regression model since it was not statistically significantly associated with sedentary behaviour. As a first step, all variables significantly predicting sedentary behaviour, age, gender and education were introduced to the regression model (Table 4). People who reported low local opportunities were 31\% more likely to be sedentary that those who perceived high local opportunities. Those who perceived low social support from personal environment were over twice as likely to be sedentary than those who reported high social support from personal environment. Low social support from the "media environment" in turn was "protective" for active behaviour, since those who reported low media support were half likely to be sedentary compared to those with high social support from media environment.

\section{[ TABLE 4 ]}

Those who were poorly informed about programmes and actions for sport and physical activity were $77 \%$ more likely to be inactive compared to those who were well informed. People who felt that health policy doesn't promote people's physical activity and sport were $57 \%$ more likely to be inactive compared to those who felt that health policy promotes people's physical activity and sport. The more educated were less likely to be inactive.

As a second step the country variable was included in the regression model (Table 5). The country variable altered the local opportunity variable, since it was not a statistically significant predictor of sedentary behaviour anymore. In addition, the health policy variable lost its predictive power. Much of this was explained by the country (regional) variable, with Spain showing a three- fold increased likelihood of non-participation, and Finland and Switzerland lower likelihood of non- participation. 
Stahl, T., Rütten, A., Nutbeam, D., Bauman, A., Kannas, L., Abel, T., Lüschen, G., Rodríguez Diaz, J.A., Vinck, J., Zee, J. van der

The importance of the social environment for physically active lifestyle: results from

an international study.

Social Science \& Medicine: 52, 2001, nr. 1, p. 1-10

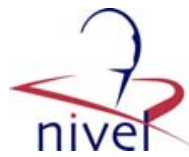

\section{[ TABLE 5 ]}

\section{DISCUSSION}

The results of this study are based on a cross-cultural health policy study that was originally designed to assess the extent of development of supportive policies for health promotion in European countries (MAREPS). Because of the primary orientation of the study and questionnaire construction there are some important shortcomings in the measures that have been used in this paper. Firstly, the physical activity measure allowed us only to categorise persons as active or inactive. This simple categorisation of activity has limited more detailed analysis of the differences between activity level groups (e.g. based on estimated energy expenditures). Other limitations of the study include the usual difficulties that arise in cross-cultural studies. Samples from the countries were not selected to represent the entire nation of the country (with the exception of the Netherlands) and the response rates varied from one country to another (from 41.9 to $69.7 \%$ ). As in every cross-cultural study, translation of common questions and the ways the concepts are interpreted in countries may have varied, and may account for some of the differences observed. For example, the exceptionally low results concerning participation in physical activity from Spain may partly be a result of a difference in under- standing of the question concerning physical activity and sport in this study (see also COMPASS, 1999). The relatively low response rate may not be as important in this examination of physical activity, since the original study was examining health policy, it is unlikely that non-response would be associated with level of physical activity. For all these reasons, this study may best be considered as a pilot study, examining key relationships between physical activity, the social environment and the physical and policy environment.

The social environment was the strongest predictor of being physically active. Those who perceived low levels of social support from their personal environment (i.e. family, friends, school and workplace) were twice more likely to be physically inactive compared to those who reported high support. Our findings strengthen previous research that has consistently found positive association between social support and physical activity in a variety of population samples (Sallis \& Owen, 1998). This finding suggests that strategies to promote greater participation in physical activity need to focus more on social norms regarding active lifestyles, and on making activity more "socially acceptable" in a wider range of settings and circumstances.

It appears that people would need to be better informed too, not so much about health risks and benefits of physical activity, but more practical and specific knowledge of programmes and actions for sport and physical activity. In this study, those who reported good awareness of local opportunities for activity were $83 \%$ more likely to be active compared to those who reported poor awareness. This finding needs confirmation from other studies too because it might be possible that active people are more likely than the inactive to make themselves aware of the local opportunities for activities.

By contrast, motivational information received from media did not seem to have the same kind of effect as specific information on available facilities and options for activity. Indeed, a surprising result is that high levels of awareness of support for physical activity from the media (journals/newspapers, TV/radio) was associated with sedentary behaviour. To understand this finding, further investigation is needed.

A supportive physical and policy environment (facilities, programmes and other opportunities) was not associated with participation in physical activity as strongly as had been anticipated. Interestingly, this variable lost its predictive power when the data were examined by including individual countries in the regression model. From this, the country-variable seems to be the most important environmental factor explaining differences in physical activity levels in different countries. This finding and the fact that there are huge differences in the physical activity levels within countries require further investigation beyond the scope of the present report. Importantly, these differences in the physical activity levels were not explained by socio- economic variables.

According to our results social cognitive theory is useful in explaining relationships between individual behaviours, perceptions of the social environment and perceptions of a supportive physical and policy environment. In line with the theory the results indicated that the better the support from 
Stahl, T., Rütten, A., Nutbeam, D., Bauman, A., Kannas, L., Abel, T., Lüschen, G.,

Rodríguez Diaz, J.A., Vinck, J., Zee, J. van der

The importance of the social environment for physically active lifestyle: results from

an international study.

Social Science \& Medicine: 52, 2001, nr. 1, p. 1-10

the social environment and from the physical and policy environment, the more likely it was that a person will be active. The findings remained powerful after controlling for socio-economic variables.

As suggested by the social cognitive theory, and according to our results, social, policy and physical environments should be made more favourable for physical activity. For example observational and inter- active learning techniques/principles can be applied to modify the social environment. Health promotion and health education interventions should pay more attention to the influence of role models and importance of observational learning by observing others. Modification of the physical environment (provide cues about acceptable behaviour) can change the perceived supportiveness of an environment.

This study generates the hypotheses and raises the questions that in a preliminary way, there appears to be some relationships between aspects of physical and social environment and physical activity participation. However, future research, using cross-culturally validated activity measures, and some more objective measures of policies that promote physical activity, are needed to refine and clarify this.

\section{TABLES}

Table 5

Logistic regression examining the variables associated with sedentary behaviour, model 2 (including country variable) ${ }^{\mathrm{a}}$

\begin{tabular}{|c|c|c|c|}
\hline Variable & Odds ratio & $95 \%$ confidence interval & $p$ \\
\hline Low support from local environment (reference, high support) & 0.94 & $(0.75,1.19)$ & 0.614 \\
\hline Low social support from personal environment (reference, high support) & 2.15 & $(1.72,2.68)$ & $<0.001$ \\
\hline Low social support from media environment (reference, high support) & 0.52 & $(0.42,0.64)$ & $<0.001$ \\
\hline Poorly informed of programmes and actions (reference, well informed) & 1.70 & $(1.37,2.11)$ & $<0.001$ \\
\hline $\begin{array}{l}\text { Doesn't feel that health politics promotes people's physical activity } \\
\text { (reference, feels that health policy promotes...) }\end{array}$ & 1.19 & $(0.96,1.47)$ & 0.113 \\
\hline Sex (reference, male) & 0.88 & $(0.72,1.08)$ & 0.222 \\
\hline Age (years) (reference 18-29) & & & 0.622 \\
\hline $30-44$ & 1.17 & $(0.88,1.57)$ & \\
\hline $45-59$ & 1.07 & $(0.78,1.48)$ & \\
\hline $60+$ & 1.20 & $(0.86,1.68)$ & \\
\hline Education (years) (reference 0-9) & & & $<0.001$ \\
\hline $10-14$ & 0.71 & $(0.54,0.92)$ & \\
\hline $15-20$ & 0.50 & $(0.39,0.65)$ & $<0.001$ \\
\hline \multicolumn{4}{|l|}{ Country (reference Germany, eastern region) } \\
\hline Germany, western region & 0.84 & $(0.62,1.14)$ & \\
\hline Finland & 0.26 & $(0.16,0.42)$ & \\
\hline The Netherlands & 0.58 & $(0.33,1.03)$ & \\
\hline Switzerland & 0.42 & $(0.29,0.62)$ & \\
\hline Belgium & 1.20 & $(0.87,1.67)$ & \\
\hline Spain & 3.16 & $(2.26,4.41)$ & \\
\hline
\end{tabular}

${ }^{\text {a }}$ Goodness of fit, overall percentage correctly classified $=74.6 \%$. 
Stahl, T., Rütten, A., Nutbeam, D., Bauman, A., Kannas, L., Abel, T., Lüschen, G., Rodríguez Diaz, J.A., Vinck, J., Zee, J. van der

The importance of the social environment for physically active lifestyle: results from an international study.

Social Science \& Medicine: 52, 2001, nr. 1, p. 1-10

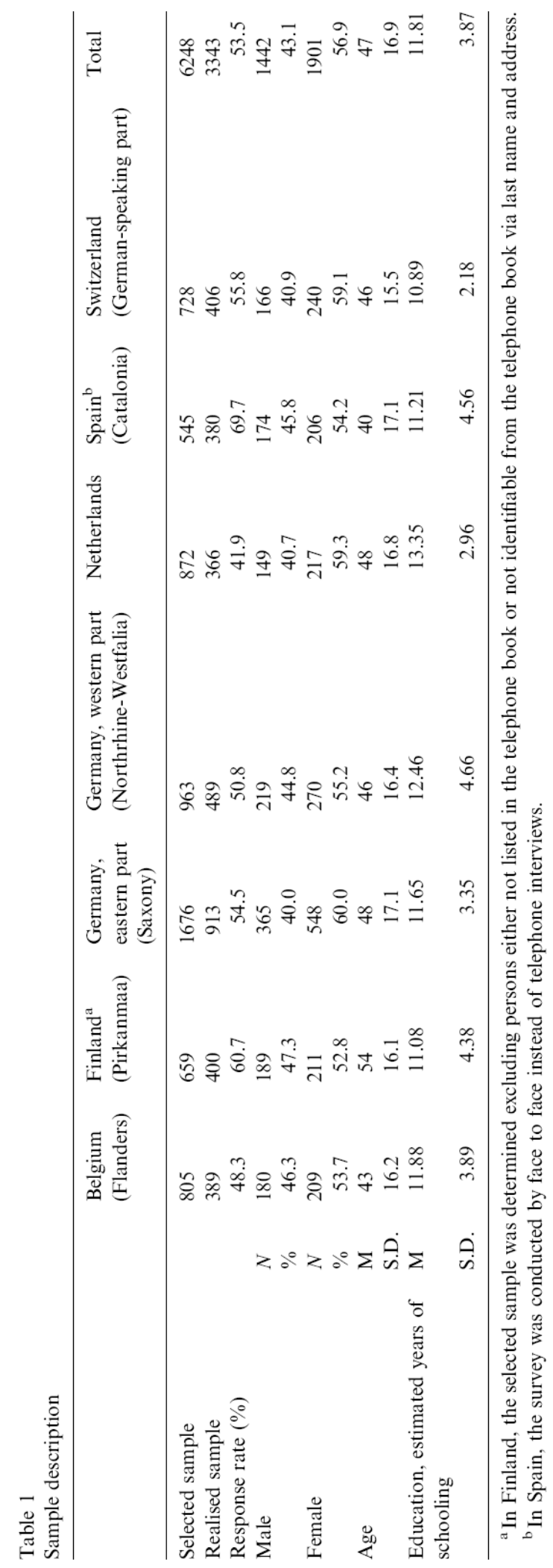


Stahl, T., Rütten, A., Nutbeam, D., Bauman, A., Kannas, L., Abel, T., Lüschen, G.,

Rodríguez Diaz, J.A., Vinck, J., Zee, J. van der

The importance of the social environment for physically active lifestyle: results from

an international study.

Social Science \& Medicine: 52, 2001, nr. 1, p. 1-10

Table 2

Scale constructions and items of the social environment and physical and policy environment variables

\begin{tabular}{|c|c|c|c|c|c|}
\hline \multirow[b]{2}{*}{ Factor analysis } & \multicolumn{3}{|c|}{ Factor loadings } & \multirow[b]{2}{*}{ Communality } & \multirow[b]{2}{*}{ Cronbach $\alpha($ sum index $)$} \\
\hline & $\mathrm{F} 1$ & $\mathrm{~F} 2$ & F3 & & \\
\hline \multicolumn{6}{|l|}{$\begin{array}{l}\text { How much have you been motivated to sports and physical activity } \\
\text { by: }\end{array}$} \\
\hline F1: personal environment-scale & & & & & 0.57 \\
\hline Friends/acquaintances & 0.76 & -0.27 & 0.12 & 0.60 & \\
\hline Spouse/family/relatives & 0.73 & -0.20 & 0.18 & 0.54 & \\
\hline Workplace & 0.58 & -0.23 & 0.36 & 0.37 & \\
\hline School & 0.51 & -0.32 & 0.29 & 0.29 & \\
\hline F2: Media environment-scale & & & & & 0.81 \\
\hline Journals/newspapers & 0.31 & -0.91 & 0.32 & 0.83 & \\
\hline $\mathrm{TV} /$ radio & 0.31 & -0.90 & 0.35 & 0.82 & \\
\hline F3: External environment-scale & & & & & 0.57 \\
\hline Health insurance & 0.11 & -0.29 & 0.74 & 0.57 & \\
\hline Doctor & 0.25 & -0.25 & 0.71 & 0.50 & \\
\hline Politicians & 0.28 & -0.27 & 0.67 & 0.45 & \\
\hline Community & 0.43 & -0.41 & 0.55 & 0.40 & \\
\hline \multicolumn{6}{|l|}{ Sum index: } \\
\hline Local opportunity-scale & & & & & 0.74 \\
\hline $\begin{array}{l}\text { My residential area offers many opportunities to be physically } \\
\text { active (item) }\end{array}$ & & & & & \\
\hline $\begin{array}{l}\text { Local sports clubs and other providers in my community offer } \\
\text { many opportunities (item) }\end{array}$ & & & & & \\
\hline $\begin{array}{l}\text { My community doesn't do enough for the citizens and their } \\
\text { physical activities (item) }\end{array}$ & & & & & \\
\hline \multicolumn{6}{|l|}{ Items (were used as individual items in the analysis): } \\
\hline $\begin{array}{l}\text { How well you feel informed about programs and actions for the } \\
\text { promotion of sports and physical activity? }\end{array}$ & & & & & \\
\hline To what extent do you think that health policy in our country & & & & & \\
\hline
\end{tabular}

Table 4

Logistic regression examining the variables associated with sedentary behaviour, model 1 (excluding country variable) ${ }^{\mathrm{a}}$

\begin{tabular}{|c|c|c|c|}
\hline Variable & Odds ratio & $95 \%$ confidence interval & $p$ \\
\hline Low support from local environment (reference, high support) & 1.31 & $(1.06,1.61)$ & 0.012 \\
\hline Low social support from personal environment (reference, high support) & 2.02 & $(1.64,2.49)$ & $<0.001$ \\
\hline Low social support from media environment (reference, high support) & 0.52 & $(0.42,0.64)$ & $<0.001$ \\
\hline Poorly informed of programmes and actions (reference, well informed) & 1.77 & $(1.44,2.18)$ & $<0.001$ \\
\hline $\begin{array}{l}\text { Doesn't feel that health politics promotes people's physical activity } \\
\text { (reference, feels that health policy promotes...) }\end{array}$ & 1.57 & $(1.29,1.91)$ & $<0.001$ \\
\hline Sex (reference, male) & 0.90 & $(0.74,1.10)$ & 0.302 \\
\hline Age (years) (reference 18-29) & & & 0.794 \\
\hline $30-44$ & 0.95 & $(0.72,1.25)$ & \\
\hline $45-59$ & 0.87 & $(0.64,1.17)$ & \\
\hline $60+$ & 0.88 & $(0.64,1.22)$ & \\
\hline Education (years) (reference 0-9) & & & $<0.001$ \\
\hline $10-14$ & 0.73 & $(0.57,0.94)$ & \\
\hline $15-20$ & 0.43 & $(0.34,0.55)$ & \\
\hline
\end{tabular}

${ }^{\mathrm{a}}$ Goodness of fit, overall percentage correctly classified $=72.4 \%$. 
Stahl, T., Rütten, A., Nutbeam, D., Bauman, A., Kannas, L., Abel, T., Lüschen, G., Rodríguez Diaz, J.A., Vinck, J., Zee, J. van der

The importance of the social environment for physically active lifestyle: results from

an international study.

Social Science \& Medicine: 52, 2001, nr. 1, p. 1-10

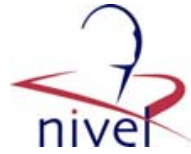

Table 3

Comparisons of the characteristics of active and inactive persons

\begin{tabular}{|c|c|c|c|c|}
\hline Variable & $N$ & Inactive $(\%)$ & Active $(\%)$ & $p$ (Chi-square) \\
\hline \multicolumn{5}{|l|}{ Sex } \\
\hline Female & 1900 & 32.3 & 67.7 & \\
\hline Male & 1441 & 30.1 & 69.9 & 0.186 \\
\hline \multicolumn{5}{|l|}{ Age (years) } \\
\hline $18-29$ & 597 & 32.3 & 67.7 & \\
\hline $30-44$ & 1025 & 29.4 & 70.6 & \\
\hline $45-59$ & 847 & 31.3 & 68.7 & \\
\hline $60+$ & 840 & 33.1 & 66.9 & 0.343 \\
\hline \multicolumn{5}{|l|}{ Education (years) } \\
\hline $0-9$ & 1201 & 40.0 & 60.0 & \\
\hline $10-14$ & 898 & 31.5 & 68.5 & \\
\hline $15-20$ & 1184 & 21.3 & 78.7 & $<0.001$ \\
\hline \multicolumn{5}{|c|}{ Physical and policy environment } \\
\hline \multicolumn{5}{|c|}{ Local opportunities for physical activity (scale): } \\
\hline Low & 1483 & 36.3 & 63.7 & \\
\hline High & 1408 & 24.9 & 75.1 & $<0.001$ \\
\hline \multicolumn{5}{|c|}{ Informed about programmes and actions: } \\
\hline Poorly & 1476 & 38.6 & 61.4 & \\
\hline Well & 1775 & 24.7 & 75.3 & $<0.001$ \\
\hline \multicolumn{5}{|c|}{ Health policy contributes whether people do physical activity } \\
\hline Don't agree & 1431 & 36.5 & 63.5 & \\
\hline Agree & 1798 & 26.7 & 73.3 & $<0.001$ \\
\hline \multicolumn{5}{|l|}{ Social environment } \\
\hline \multicolumn{5}{|l|}{ Personal environment (scale) } \\
\hline Low & 1402 & 37.7 & 62.3 & \\
\hline High & 1324 & 24.5 & 75.5 & $<0.001$ \\
\hline \multicolumn{5}{|l|}{ Media environment (scale) } \\
\hline Low & 1689 & 27.7 & 72.3 & \\
\hline High & 1601 & 34.5 & 65.5 & $<0.001$ \\
\hline \multicolumn{5}{|l|}{ External environment (scale) } \\
\hline Low & 2003 & 31.3 & 68.7 & \\
\hline High & 1180 & 29.1 & 70.9 & 0.186 \\
\hline \multicolumn{5}{|l|}{ Countries } \\
\hline Germany, eastern region & 911 & 35.9 & 64.1 & \\
\hline Germany, western region & 489 & 29.9 & 70.1 & \\
\hline Finland & 400 & 12.0 & 88.0 & \\
\hline The Netherlands & 366 & 21.3 & 78.7 & \\
\hline Switzerland & 406 & 16.5 & 83.5 & \\
\hline Belgium & 389 & 36.8 & 63.2 & \\
\hline Spain & 380 & 62.6 & 37.4 & $<0.001$ \\
\hline
\end{tabular}

\section{REFERENCES}

1. Antonucci, T. C. (1990). Social supports and social relation- ships. In R. H. Binstock, \& L. K. George, Handbook of aging and the social sciences. San Diego, CA: Academic Press.

2. Antonucci, T. C., Akiyama, H., \& Lansford, J. E. (1998). Negative effects of close social relations. Family Relations, 47, 379-384.

3. Babbie, E. R. (1990). Survey research methods. Belmont, CA: Wadsworth.

4. Baranowski, T., Anderson, C., \& Carmack, C. (1998). Mediating variable framework in physical activity interventions. American Journal of Preventive Medicine, 15, 266-297.

5. Baranowski, T., Perry, C. L., \& Parcel, G. S. (1996). How individuals, environments, and health behavior interact: social cognitive theory. In K. Glanz, F. M. Lewis, \& B. K. Rimer, Health behavior and health education. theory, research and practice (pp. 153-178). San Francisco, CA: Jossey-Bass.

6. Biener, L., Abrams, D. B., Follick, M. J., \& Dean, L. (1989). A comparative evaluation of a restrictive smoking policy in a general hospital. American Journal of Public Health, 79, 192195.

7. Brownson, R. C., Koffman, D. M., Novotny, T. E., Hughes, R. G., \& Eriksen, M. P. (1995). Environmental and policy interventions to control tobacco use and prevent cardiovascular disease. Health Education Quarterly, 22, 478-498. 
Stahl, T., Rütten, A., Nutbeam, D., Bauman, A., Kannas, L., Abel, T., Lüschen, G.,

Rodríguez Diaz, J.A., Vinck, J., Zee, J. van der

The importance of the social environment for physically active lifestyle: results from

an international study.

Social Science \& Medicine: 52, 2001, nr. 1, p. 1-10

8. Brownson, R. C., Schmid, T. L., King, A. C., Eyler, A. A., Pratt, M., Murayi, T., Mayer, J. P., \& Brown, D. R. (1998). Support for policy interventions to increase physical activity in rural Missouri. American Journal of Health Promotion, 12, 263-266.

9. COMPASS. (1999). A project seeking the co-ordinated monitoring of participation in sports in Europe. UK Sport, CONI, Sport England, Council of Europe.

10. Corti, B., Donovan, R. J., Castine, R. M., Holman, C. D. J., \& Shilton, T. (1995). Encouraging the sedentary to be active every day: qualitative formative research. Health Promotion Journal of Australia, 5, 10-17.

11. Corti, B., Donovan, R. J., \& Holman, C. D. J. (1996). Factors influencing the use of physical activity facilities: results from qualitative research. Health Promotion Journal of Australia, 6 , 16-21.

12. Coureya, K. S., \& McAuley, E. (1994). Are there different determinants of the frequency, intensity, and duration of physical activity. Behavioral Medicine, 20, 84-90.

13. DiLorenzo, T. M., Stucky-Ropp, R. C., Vander Wal, J. S., \& Gotham, H. J. (1998). Determinants of exercise among children. II. A longitudinal analysis. Preventive Medicine, 27, 470-477.

14. Dishman, R. K., Oldenburg, B., O'Neal, H., \& Shephard, R. J. (1998). Worksite physical activity interventions. American Journal of Preventive Medicine, 15, 344-361.

15. Edmundson, E., Parcel, G. S., Feldman, H. A., Elder, J., Perry, C. L., Johnson, C. C., Williston, B. J., Stone, E. J., Yang, M., Lytle, L., \& Webber, L. (1996). The effects of the child and adolescent trial for cardiovascular health upon psychosocial determinants of diet and physical activity behaviour. Preventive Medicine, 25, 442-454.

16. Fowler, F. J. (1984). Survey research methods. Beverly Hills, CA: SAGE.

17. Frankish, C. J., Milligan, C. D., \& Reid, C. (1998). A review of relationships between active living and determinants of health. Social Science \& Medicine, 47, 287-301.

18. Heaney, C. A., \& Israel, B. A. (1996). Social networks and social support. In K. Glanz, F. M. Lewis, \& B. K. Rimer, Health behavior and health education. Theory, research and practice (pp. 179-205). San Francisco, CA: Jossey-Bass.

19. Holman, C. D. J. (1997). Measuring the occurrence of health- promoting interactions within environment. Australian and New Zealand Journal of Public Health, 21, 360-364.

20. House, J. S., Umberson, D., \& Landis, K. R. (1988a). Structures and processes of social support. Annual Review of Sociology, 14, 293-318.

21. House, J. S., Landis, K. R., \& Umberson, D. (1988b). Social relationships and health. Science, $241,540-545$.

22. King, A. C., Jeffery, R. W., Fridinger, F., Dusenbury, L., Provence, S., Hedlund, S. A., \& Spangler, K. (1995). Environmental and policy approaches to cardiovascular disease prevention through physical activity: issues and opportunities. Health Education Quarterly, 22, 499-511.

23. Laitakari, J., Vuori, I., \& Oja, P. (1996). Is long-term maintenance of health-related physical activity possible? An analysis of concepts and evidence. Health Education Re- search, 11, 463-477.

24. Leslie, E., Owen, N., Salmon, J., Bauman, A., Sallis, J. F., \& Sing, Kai Lo (1999). Insufficiently active Australian college students: perceived personal, social, and environmental influences. Preventive Medicine, 28, 20-27.

25. Linenger, J. M., Chesson, C. V., \& Nice, D. C. (1991). Physical fitness gains following simple environmental change. Amer- ican Journal of Preventive Medicine, 7, 298-310.

26. Luepker, R. V., Perry, C. L., McKinlay, S. M., Nader, P. R., Parcel, G. S., Stone, E. J., Webber, L. S., Elder, J. P., Feldman, H. A., Johnson, C. C., Kelder, S. H., \& Wu, M. (1996). Outcomes of a trial to improve children's dietary patterns and physical activity: the child and adolescent trial for cardiovascular health (CATCH). Journal of the American Medical Association, 275, 768-776.

27. Quick, J. D., Nelson, D., Matuszek, P., Whittington, J. L., \& Quick, J. C. (1996). Social support, secure attachments, and health. In C. L. Cooper, Handbook of stress, medicine, and health. Boca Raton, FL: CRC Press.

28. Rütten, A., Lüschen, G., Lengerke, Tv, Abel, T., Kannas, L., Rodriguez, Diaz J. A., Vinck, J., \& Zee, Jvd (2000). Health promotion policy in Europe - rationality, impact, and evaluation. München: Oldenbourg.

29. Sallis, J. F., Bauman, A., \& Pratt, M. (1998). Environmental and policy interventions to promote physical activity. American Journal of Preventive Medicine, 15, 379-397. 
Stahl, T., Rütten, A., Nutbeam, D., Bauman, A., Kannas, L., Abel, T., Lüschen, G., Rodríguez Diaz, J.A., Vinck, J., Zee, J. van der

The importance of the social environment for physically active lifestyle: results from an international study.

Social Science \& Medicine: 52, 2001, nr. 1, p. 1-10

30. Sallis, J. F., Grossman, M. S., Pinski, R. B., Patterson, T. L., \& Nader, P. R. (1987). The development of scales to measure social support for diet and exercise behaviors. Preventive Medicine, 16, 825-836.

31. Sallis, J. F., Hovell, M. F., \& Hofstetter, C. R. (1992). Predictors of adoption and maintenance of vigorous physical activity in men and women. Preventive Medicine, 21, 237-251.

32. Sallis, J. F., Hovell, M. F., Hofstetter, C. R., Faucher, P., Elder, J. P., Blanchard, J., Casperson, C. J., Powell, K. E., \& Christenson, G. M. (1989). A multivariate study of determinants of vigorous exercise in a community sample. Preventive Medicine, 18, 20-34.

33. Sallis, J. F., Hovell, M. F., Hofstetter, C. R., Elder, J. P., Hackley, M., Caspersen, C. J., \& Powell, K. E. (1990). Distance between homes and exercise facilities related to frequency of exercise among San Diego residents. Public Health Reports, 105, 179-185.

34. Sallis, J. F., Johnson, M. F., Calfas, K. J., Caparosa, S., \& Nichols, J. F. (1997). Assessing perceived physical environ- mental variables that may influence physical activity. Research Quarterly for Exercise and Sport, 68, 345-351.

35. Sallis, J. F., \& Owen, N. (1998). Physical activity and behavioral medicine. Behavioral medicine and health psychology, Series 3. Thousand Oaks, CA: SAGE.

36. Schmid, T. L., Pratt, M., \& Howze, E. (1995). Policy as intervention: environmental and policy approaches to the prevention of cardiovascular disease. American Journal of Public Health, 85, 1207-1211.

37. Shephard, R. J. (1996). Worksite fitness and exercise programs: a review of methodology and health impact. American Journal of Health Promotion, 10, 436-452.

38. Simons-Morton, B. G., Parcel, G. S., Baronowski, T., Forthofer, R. , \& O'Hara, N. M. (1991). Promoting diet and physical activity among children: results of a school based intervention study. American Journal of Public Health, 81, 986-991.

39. Steptoe, A., Wardle, J., Fuller, R., Holte, A., Justo, J., Sanderman, R., \& Wichstrom, L. (1997). Leisure-time physical exercise: prevalence, attitudinal correlates, and behavioral correlates among young Europeans from 21 countries. Preventive Medicine, 26, 845-854.

40. Sternfeld, B., Ainsworth, B. E., \& Quesenberry Jr, C. P. (1999). Physical activity patterns in a diverse population of women. Preventive Medicine, 28, 313-323.

41. Stone, E. J., Mckenzie, T. L., Welk, G. J., \& Booth, M. L. (1998). Effects of physical activity interventions in youth - review and synthesis. American Journal of Preventive Medicine, 15, 298-314.

42. Turner, R. J., \& Marino, F. (1994). Social support and social structure: a descriptive epidemiology. Journal of Health and Social Behavior, 35, 193-212.

43. Vartiainen, E., Puska, P., Jousilahti, P., Korhonen, H. J., Tuomilehto, J., \& Nissinen, A. (1994). Twenty-year trends in coronary risk factors in north Karelia and in other areas of Finland. International Journal of Epidemiology, 23, 495-504. 